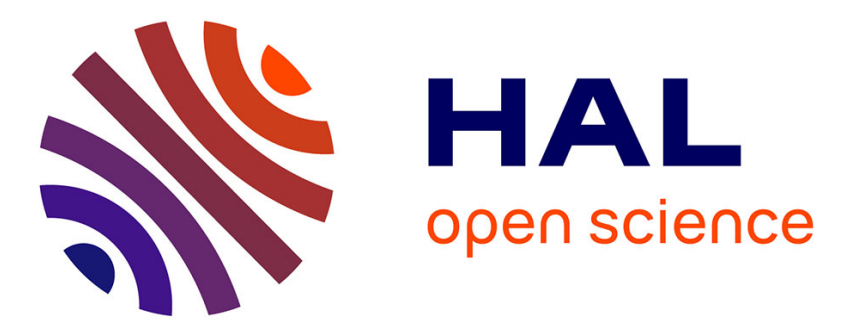

\title{
IMU Based Detection of Freezing of Gait and Festination in Parkinson's Disease
}

Christine Azevedo Coste, Benoît Sijobert, Jennifer Denys, Christian Geny

\section{To cite this version:}

Christine Azevedo Coste, Benoît Sijobert, Jennifer Denys, Christian Geny. IMU Based Detection of Freezing of Gait and Festination in Parkinson's Disease. IFESS: International Functional Electrical Stimulation Society, Sep 2014, Kuala Lumpur, Malaysia. 10.13140/2.1.1587.1366 . hal-01096479

\section{HAL Id: hal-01096479 \\ https://inria.hal.science/hal-01096479}

Submitted on 17 Dec 2014

HAL is a multi-disciplinary open access archive for the deposit and dissemination of scientific research documents, whether they are published or not. The documents may come from teaching and research institutions in France or abroad, or from public or private research centers.
L'archive ouverte pluridisciplinaire HAL, est destinée au dépôt et à la diffusion de documents scientifiques de niveau recherche, publiés ou non, émanant des établissements d'enseignement et de recherche français ou étrangers, des laboratoires publics ou privés. 


\section{IMU Based Detection of Freezing of Gait and Festination in Parkinson's Disease}

\author{
Benoît SIJOBERT \\ INRIA - LIRMM \\ Montpellier, France \\ benoit.sijobert@inria.fr \\ Jennifer DENYS \\ UM2 - INRIA \\ Montpellier, France \\ jennifer.denys@inria.fr
}

\begin{abstract}
Freezing of gait (FOG) and festination are common symptoms in Parkinson Disease. They affect gait pattern and are associated to fall risks. We aim at early detection of FOG and festination episodes in order to trigger FES assistance. In this paper we present preliminary experimental results of FOG and festination detection including frequency analysis and gait parameters changes. The proposed solution is based on one wireless inertial sensor placed on the patient shank.
\end{abstract}

Index Terms - freezing of gait (FOG); festination; inertial measurement units (IMU); gait parameters estimation; Parkinson's disease;

\section{INTRODUCTION}

Parkinson's disease (PD) is the second most common neurodegenerative disorder $[1,2]$. This chronic disease is associated to gait impairment and high risk of falls [3]. Freezing of gait (FOG) is defined as "an episodic inability (lasting seconds) to generate effective stepping in the absence of any known cause other than Parkinsonism or high-level gait disorders"[4]. Festination while walking is defined as a tendency to move forward with increasingly rapid, but ever smaller steps [5].

Focused attention and external stimuli can help patient to overcome FOG episodes [6]. Auditory rhythmic stimulation and visual marks on the ground are classically used [7,8]. Functional Electrical Stimulation (FES) has also been tested and preliminary results show FOG reduction observed during FES-assisted gait of PD patients $[9,10]$.

Moore et al. have proposed a technique to identify FOG episodes [11] based on the frequency properties of leg vertical accelerations. The approach is based on the hypothesis that FOG occurrences are associated to trembling motion, which affect limb acceleration signal. They have introduced the socalled freeze index (FI): the ratio between the signal (limb acceleration) power in the "freeze" band and the signal power in the "locomotor" band. The FI method was validated using one to seven accelerometers mounted on patients with satisfactory detection results [11]. Our objective is to propose an approach to detect as early as possible both FOG and

\author{
Christine AZEVEDO COSTE \\ INRIA - LIRMM \\ Montpellier, France \\ christine.azevedo@inria.fr \\ Christian GENY \\ CHU Gui de Chaulliac, Neurologie \\ Montpellier, France \\ c-geny@,chu-montpellier.fr
}

festination episodes in order to later propose a robust solution for real-time control of FES-assistance [12]. Furthermore we intend to propose a solution based on a minimal number of embedded sensors and detection algorithms for future real-time applications.

In the following we will detail the proposed methodology and report preliminary results on $7 \mathrm{PD}$ patients.

\section{FreEZING OF Gait Detection}

As described in previous section, the freezing index as introduced by Moore et al. [14-15] is based on a frequency analysis. For each instant $t, \operatorname{FI}(t)$ is defined as the square of the area under the power spectra of a $6 \mathrm{~s}$ window of data (centered at time $\mathrm{t})$ in the "freeze" band $(3-8 \mathrm{~Hz})$, divided by the square of the area under the power spectra in the "locomotor" band $(0.5-3 \mathrm{~Hz})$. Based on FOG duration, the optimal window width has to approximately be twice the duration of the shortest FOG event to be detected. In their article, Moore et al. have chosen a threshold as the mean plus one S.D. of the peak FI from nine epochs of volitional standing, such that FI values above this limit are designated as FOG.

We have introduced a new approach based on gait pattern changes observation for festination and FOG events detection [12]: the FOG criterion (FOGC). Based on the continuous evaluation of two gait parameters: cadence and stride length, our hypothesis is that the cadence should increase whereas the stride length decreases (festination) before a FOG event occurs.

For each detected stride $\mathbf{n}$, its cadence $(\mathbf{C n})$, its length $(\mathbf{L n})$, the related following criterion is computed:

$$
F O G C_{\mathrm{n}}=\frac{C_{n \cdot} \cdot L_{\min }}{C_{\max }\left(L_{n}+L_{\min }\right)}
$$

where: $\mathbf{C m a x}$ (5 strides/s) and $\mathbf{L} \min (5 \mathrm{~cm})$ are respectively the expected maximal value for the cadence and minimal value for the length of strides (for bounding the criterion to 1).

A high value of the FOGC is associated to a freezing of gait event. A criterion increase should indicate an imminent FOG 
episode. The FOGC value needs to be compared to a threshold adjusted for each patient.

Gait segmentation and stride length calculation are performed using inertia sensor-based walking speed estimation methods [13]. Using gyroscopic data for stride segmentation, the horizontal speed is calculated from the velocity of the leg at the stride onset and offset (gyroscopic signal) combined with the accelerometric data integration. At the end of each stride, a proportional correction is performed, based on the difference between the velocity estimated by the algorithm and the values measured by gyroscopic sensors.

\section{EXPERIMENTAL SECTION}

We placed a wireless inertial measurement unit (IMU) on patient shank $\left(\mathrm{HikoB}^{\odot}\right)($ Figure 1$)$. The IMU consists of a 3D accelerometer and a 3D gyrometer whose data is stored on a micro SD card at a frequency of $200 \mathrm{~Hz}$. A video camera is synchronized with the inertial sensor. The patient gait is analyzed offline based on the video recordings. A clinician spots FOG events and classifies them as follows: (1) slight modification of the gait - with no falling risk (green); (2) main gait modification with falling risk (orange); (3) FOG - gait is blocked with or without festination (red).

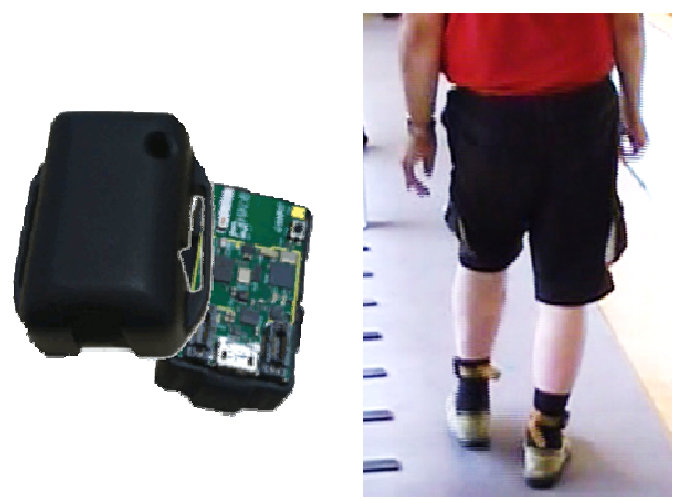

Fig. 1. HikoB ${ }^{\mathcal{C}}$ inertial measurement unit (Left) and experiment picture (Right)

7 patients, (6 males, 1 female, $70 \pm 5$ years old) participated to this preliminary study. The patients were asked to walk along a $20 \mathrm{~m}$ corridor and several dual tasks were proposed in order to maximize the number of FOG occurrences. Local ethical committee approved the study.

\section{RESULTS AND DISCUSSION}

A total amount of $97 \mathrm{~min}$ of gait was recorded and analyzed. The neurologist identified and labeled 50 events (Table 1). IMU sensor data was processed in order to compute FI and FOGC indexes (Figure 2). The FI method detected 32 of these episodes and the FOGC method detected 41 of these episodes. Concerning the 31 main FOG events (labeled red and orange), FI "missed" 11 FOG events and FOGC missed only 5 of them.
TABLE I. FOG EPISODES DETECTED THROUGH VIDEO ANALYSIS, VIA FI AND FOGC ALGORITHMS.

\begin{tabular}{|l|c|c|c|}
\hline $\begin{array}{c}\text { FOG } \\
\text { intensity }\end{array}$ & Video & FI & FOGC \\
\hline Green & 19 & 10 & 14 \\
\hline Orange & 12 & 6 & 10 \\
\hline Red & 19 & 16 & 17 \\
\hline $\begin{array}{l}\text { False } \\
\text { Positives }\end{array}$ & 0 & 18 & 14 \\
\hline
\end{tabular}
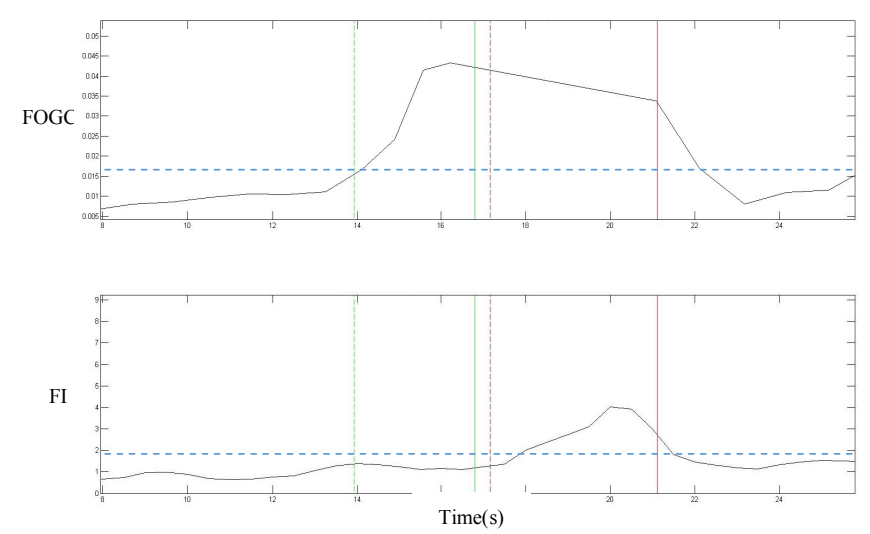

Fig. 2. Example of detection performances. Around $16 \mathrm{~s}$, an important FOG event (Red) preceded by festination (Green) is detected by FOGC (Top). The FI increases beyond its threshold and detects also the FOG, but not the festination part (Bottom).

These observations emphasize the FOG heterogeneous characteristics and show that FI method is not able to detect all the episodes. Additionally, from the videos, we were able to clearly identify 3 festination episodes preceding FOG events (Figure 2). None of them was detected by the FI method whereas FOGC detected all of them. Due to its definition FI is not sensitive to festination as the method uses power frequency band ratios observed on vertical acceleration changes.

\section{CONCLUSIONS/OUTLOOK}

Freezing and festination of gait in Parkinson's Disease are associated with a high fall risk. Objectively detecting FOG and festination episodes during the daily activities of a patient would allow to better assess a patient's state and the clinical effects of treatments. Furthermore real-time detection of those FOG events could allow triggering assistive/cueing devices at the right time. Indeed, if visual or auditory cues can help patients to reduce freezing occurrences, the efficiency decreases within time. Triggering the systems only when needed may be a solution to reduce the habituation effect. FI index proposed by Moore et al. detects changes in the power spectra of inertial signals and makes it possible to detect FOG events. IMU data allow going further in the analysis of gait by estimating various parameters. The interpretation of data is more intuitive as the variables considered can be linked to walking observations. We demonstrated here that stride length and cadence could for instance be interesting to observe in 
order to detect gait changes including FOG and festination. In the future we will extend the approach by observing other gait parameters and perform experiments on a larger population in order to validate our method. We believe the FI index could be associated to methods based on gait parameters in order to detect walk patterns modification and possibly anticipate the occurrence of a FOG event. In the future we aim at piloting an electrical stimulator based on festination and freezing detection.

\section{ACKNOWLEDGMENT}

This study was supported by two national fundings: AOI (CHU Montpellier) and ADT SENSBIO INRIA. We thank Roger Pissard-Gibollet, research engineer, for the technology development and protocol setup and Mourad Benoussaad for his assistance during experiments.

\section{REFERENCES}

[1] Vandenbossche, J.; Deroost, N.; Soetens, E.; Coomans, D.; Spildooren, J.; Vercruysse, S.; Nieuwboer, A.; Kerckhofs, E. Freezing of gait in Parkinson's disease: Disturbances in automaticity and control. Front. Hum. Neurosci. 2013, 6, 356.

[2] Jankovic, J. Parkinson's disease: Clinical features and diagnosis. J. Neurol. Neurosurg. Psychiatry 2008, 79, 368-376.

[3] Helly, M.A.; Reid, W.G.; Adena, M.A.; Halliday, G.M.; Morris, J.G. The Sydney multicenter study of Parkinson's disease: The inevitability of dementia at 20 years. Mov. Disord. 2008, 23, 837-844.

[4] Nieuwboer, A.; Giladi, N. Understanding and treating freezing of gait in Parkinsonism, proposed working definition, and setting the stage. Mov. Disord. 2008, 23, 1639-1640.

[5] Bloem, B.R.; Hausdorff, J.M.; Visser, J.E.; Giladi, N. Falls and freezing of gait in Parkinson's disease: A review of two interconnected, episodic phenomena. Mov. Disord. 2004, 19, 871-884.

[6] Rahman, S.; Griffin, H.J.; Quinn, N.P.; Jahanshahi, M. The factors that induce or overcome freezing of gait in Parkinson's disease. Behav. Neurol. 2008, 19, 127-136.

[7] Velik, R.; Hoffmann, U.; Zabaleta, H.; Marti Masso, J.F.; Keller, T. The effect of visual cues on the number and duration of freezing episodes in Parkinson's patients. In Proceedings of the 2012 Annual International Conference of the IEEE Engineering in Medicine and Biology Society,

San Diego, CA, USA, 28 August-1 September 2012; pp. 4656-4659.

[8] Young, W.R.; Rodger, M.W.M.; Craig, C.M. Auditory observation of stepping actions can cue both spatial and temporal components of gait in Parkinson's disease patients. Neuropsychologia 2014, 57C, 140-153.

[9] Djurić-Jovičić, M.; Radovanović, S.; Petrović, I.; Azevedo Coste, C.; Mann, G.; Popović, M.B. The impact of functional electrical stimulation (FES) on freezing of gait (FOG) in patients with Parkinson's disease. Clin. Neurophysiol. 2013, 124, e11.

[10] Mann, G.E.; Finn, S.M.; Taylor, P.N. A pilot study to investigate the feasibility of electrical stimulation to assist gait in Parkinson's disease. Neuromodulation 2008, 11, 143-149.

[11] Moore, S.T.; Yungher, D.A.; Morris, T.R.; Dilda, V.; MacDougall, H.G.; Shine, J.M.; Naismith, S. L.; Lewis, S.J.G. Autonomous identification of freezing of gait in Parkinson's disease from lower-body segmental accelerometry. J. Neuroeng. Rehabil. 2013, 10, doi:10.1186/1743-0003-10-19.

[12] Azevedo Coste, C.; Sijobert, B.; Pissard-Gibollet, R.; Pasquier, M.; Espiau, B.; Geny, C.

Detection of Freezing of Gait in Parkinson Disease: Preliminary Results. Sensors 2014, 14, 6819-6827

[13] Laudanski, A.M.; Yang, S.; Li, Q. A concurrent comparison of inertia sensor-based walking speed estimation methods. In Proceedings of the Annual International Conference of the IEEE Engineering in Medicine and Biology Society, Boston, MA, USA, 30 August-3 September 2011; pp. 3484-3487.

[14] Moore, S.T.; MacDougall, H.G.; Gracies, J.M.; Cohen, H.S.; Ondo, W.G. Long-term monitoring of gait in Parkinson's disease. Gait Posture 2007, 26, 200-207.

[15] Moore, S.T.; MacDougall, H.G.; Ondo, W.G. Ambulatory monitoring of freezing of gait in Parkinson's disease. J. Neurosci. Methods 2008, 167, 340-348. 